\title{
An Association of Pediatric Psoriasis with Metabolic Syndrome in Thai Children: 20 Years Retrospective Study
}

\author{
Parichat Mhusakunchai \\ Leelawadee Techasatian \\ Department of Pediatric, Faculty of \\ Medicine, Khon Kaen University, Khon \\ Kaen, Thailand
}

\begin{abstract}
Purpose: To explore epidemiological data of pediatric psoriasis age under 18 years old regarding, types of psoriasis, the correlation with metabolic syndrome (MetS), treatments, and treatment outcomes of at least one year follow-up.

Patients and Methods: This was a 20-year-retrospective study of pediatric psoriasis patients in a single tertiary pediatric referral center, Faculty of Medicine, Khon Kaen University, Thailand, between January 2001 and December 2020. The diagnosis of psoriasis was based on recorded diagnosis from ICD-10, and medical record was evaluated by certified pediatricians.
\end{abstract}

Results: There were 177 pediatric psoriasis in the study population. The mean age was 10.50, SD 4.80. The mean body mass index (BMI) was 19.10 (SD 5.44). There were 52 cases (29.37\%) with MetS. Pediatric psoriasis patients over the age of 12 years old developed MetS 27 out of 70 cases ( 0.38 ) compared to the patients younger than 12 years old ( 25 out of 107 cases, 0.23 ), absolute risk reduction $=0.15,95 \% \mathrm{CI} 0.01-0.29, \mathrm{P}=0.029$. The overall outcomes of pediatric psoriasis were good even though traditional topical and systemic treatments were provided in the study population.

Conclusion: The present study revealed that there was $15 \%$ increased MetS in the pediatric psoriasis patients over the age of 12 years old as compared to the patients of prepubertal age ( $\leq 12$ years old). Increased attention to the early detection of MetS in pediatric psoriasis is recommended. Biologic therapy would be an alternative option in severe recalcitrant pediatric psoriasis cases in the future.

Keywords: metabolic syndrome, pediatrics, psoriasis, treatment, outcome

\section{Introduction}

Psoriasis is a chronic inflammatory skin disorder that affects up to $1.37 \%$ of children. ${ }^{1}$ The disease can often be highly visible and uncomfortable, contributing to impaired quality of life ${ }^{2,3}$ and necessitating effective therapy. ${ }^{3,4}$ Childhood psoriasis is a special situation that is also a management challenge for treating dermatologists. Although pediatric psoriasis has many similarities to adult psoriasis, there are differences in presentation, particularly inverse psoriasis in infants and guttate psoriasis in young children. ${ }^{5}$ The association of adult psoriasis with obesity, insulin resistance, and metabolic syndrome (MetS) has been discussed. Like in adults, the association with mentioned comorbidities were also found in childhood psoriasis, even with young children of prepubertal age. ${ }^{6,7}$ Thus, increased attention to the early detection of MetS is suggested that should be performed in all psoriasis
Correspondence: Leelawadee Techasatian Department of Pediatric, Faculty of Medicine, Khon Kaen University, Khon Kaen, Thailand

Tel $+66043363012-3$

Email leelawadee@kku.ac.th 
patients. ${ }^{8}$ Most children affected by psoriasis have mild severity that is responsive to topical treatments; however, a certain group of patients present with severe disease which is poorly controlled by traditional topical therapies and required phototherapy or systemic treatment. As is the situation with traditional systemic agents, which are commonly used in managing severe psoriasis in children, the biologics are being increasingly used in the recalcitrant disease despite limited data on long-term safety. ${ }^{9,10}$ Although pediatric psoriasis is not uncommon, limited epidemiology data are available to date. Only few studies on the epidemiology of childhood psoriasis have been published. $^{8,11,12}$ Moreover, there was worldwide geographical variation which seems to reflect the fact that psoriasis is a complex disease triggered by environmental factors in genetically susceptible subjects. ${ }^{13,14}$ Therefore, the present study was performed as a 20 -year-retrospective study of pediatric psoriasis patients in a single referral tertiary care hospital, exploring epidemiological data of pediatric psoriasis age under 18 years old regarding, types of psoriasis, the correlation with MetS, treatments (during the past 20 years), and treatment outcomes of at least one year follow-up.

\section{Patients and Methods}

\section{Data Collection}

Retrospective data from the medical record were used for statistical analysis. All diagnosed psoriasis patients with age onset of diagnosis less than 18 years old were eligible. The study was performed in a single tertiary care pediatric referral center, Faculty of Medicine, Khon Kaen University, Thailand, between January 2001 and December 2020. The diagnosis of psoriasis was based on recorded diagnosis from ICD-10 and medical records were evaluated by certified pediatricians.

A child is diagnosed with MetS if a predefined critical value exceeds for three or more of the following risk factors: (1) Hyperinsulinemia/disturbed glucose metabolism/insulin resistance, (2) Arterial hypertension, (3) Dyslipidemia, and (4) Abdominal obesity. ${ }^{8,15-18}$

\section{Statistical Methods}

At the end of the study, the collected data were analyzed using STATA software version 10 (StataCorp LP). Descriptive statistical methods-means, standard deviations (SDs), medians, and frequencies-were used to analyze the demographic data. Values of $P<0.05$ were considered to indicate statistical significance. Multinomial logistic regression and post hoc analysis were used to test for the association between the types of psoriasis, age, outcomes and MetS.

\section{Results}

There were a total of one hundred and seventy-seven pediatric psoriasis patients during the study period. The age ranged from 2 months to 18 years old. The mean age was 10.50 (SD 4.80). There were 99 (55.93\%) girls and 78 (44.07\%) boys. Taking the female to male ratio to $1.26: 1$.

There were five types of psoriasis in the present study. Guttate psoriasis was the most common (101 cases, $57.06 \%$ ), followed by plaque psoriasis (46 cases, $25.99 \%$ ), generalized pustular psoriasis (27 cases, $15.25 \%$ ), inverse psoriasis (2 cases, $1.13 \%$ ), and one case of erythrodermic psoriasis $(0.56 \%)$. Table 1 shows the demographics of psoriasis patients along with five different types.

Sixty-eight cases $(38.42 \%)$ had precipitating causes of psoriasis eruptions. Majority of the cases were triggered from infections (65 cases, 36.72\%) and three cases $(1.69 \%)$ were stress-induced. There were various infections that triggered psoriasis symptoms in the study population, these included respiratory tract infections (32 cases, $18.07 \%$ ), skin infections (23 cases, 12.99\%), and infections with unknown origins (10 cases, 5.65\%). Figure 1 shows the precipitating causes of psoriasis in the study population.

The mean body mass index (BMI) was 19.10, SD 5.44. Among 52 cases of MetS in the study population, pediatric psoriasis patients over the age of 12 years old developed MetS 27 out of 70 cases (0.38) compared to the patients younger than 12 years old (25 out of 107 cases, 0.23 ), absolute risk reduction $=0.15,95 \%$ CI $0.01-0.29, \mathrm{P}=$ 0.029 . There was no association between gender, types of psoriasis and the MetS in the study population, Table 2.

All patients received topical treatment to control psoriasis eruptions. The most common topical treatment used was topical corticosteroids prescribed in $96.61 \%$ of the study population. Other topical medications were calcipotriol, calcineurin inhibitors, and Coal tar. Various systemic treatments were used in the study population. Those were methotrexate, acitretin, cyclosporine, and oral prednisolone. Systemic antibiotics were documented to treat concurrent infections in the study population that were found in 31 cases $(17.51 \%)$. Four cases $(2.26 \%)$ received phototherapy. None of the study population received biologic treatment due to no funding issue. Figure 2 shows various treatments in the study population. 
Table I Demographic of Psoriasis Patients Along with Five Different Types

\begin{tabular}{|c|c|c|c|c|c|c|}
\hline \multirow[t]{2}{*}{ Variable } & \multirow{2}{*}{$\begin{array}{c}\text { Total } \\
(n=\mid 77)\end{array}$} & \multicolumn{5}{|c|}{ Type of Psoriasis } \\
\hline & & $\begin{array}{l}\text { Plaque Psoriasis } \\
\qquad(n=46)\end{array}$ & $\begin{array}{l}\text { Guttate } \\
\text { Psoriasis } \\
(n=101)\end{array}$ & $\begin{array}{c}\text { Generalized } \\
\text { Pustular Psoriasis } \\
\qquad(\mathrm{n}=\mathbf{2 7})\end{array}$ & $\begin{array}{c}\text { Inverse } \\
\text { Psoriasis } \\
\quad(n=2)\end{array}$ & $\begin{array}{c}\text { Erythrodermic } \\
\text { Psoriasis } \\
(n=1)\end{array}$ \\
\hline \multicolumn{7}{|l|}{ Sex } \\
\hline Male & $78(44.07)$ & $20(43.48)$ & $44(43.56)$ & $12(44.44)$ & I (50.00) & $I(100)$ \\
\hline Female & $99(55.93)$ & $26(56.52)$ & $57(56.44)$ & $15(55.56)$ & I (50.00) & $0(0)$ \\
\hline \multicolumn{7}{|l|}{ Age (years) } \\
\hline $\begin{array}{l}\text { Median(min- } \\
\max )\end{array}$ & II (0.08-18.00) & $11.96(4-17.92)$ & II.5 (0.83-18.00) & $7.5(0.08-16.25)$ & $\begin{array}{c}7(2.58- \\
\text { I I.42) }\end{array}$ & $3(3-3)$ \\
\hline Median(IQR) & II (7.17-14.17) & $11.96(8.33-15.25)$ & II.5 (7.83-14.83) & $7.5(3.17-10.67)$ & $\begin{array}{c}7(2.58- \\
\text { II.42) }\end{array}$ & $3(3-3)$ \\
\hline Mean(SD) & $10.50(4.80)$ & II.8 (3.99) & $10.92(4.75)$ & $7.22(4.69)$ & $7(6.25)$ & 3 \\
\hline \multicolumn{7}{|c|}{ Family history } \\
\hline No & $152(85.88)$ & 35 (76.09) & 91 (90.10) & $23(85.19)$ & $2(100)$ & I (100) \\
\hline Yes & $5(2.82)$ & I (2.17) & $2(1.98)$ & $2(7.4 I)$ & $0(0)$ & $0(0)$ \\
\hline$N / A$ & $20(11.30)$ & $10(21.74)$ & $8(7.92)$ & $2(7.4 I)$ & $0(0)$ & $0(0)$ \\
\hline PASI score & $(n=175)$ & $(n=46)$ & $(n=99)$ & $(n=27)$ & $(n=2)$ & $(n=1)$ \\
\hline$\leq 5$ & $104(59.43)$ & 31 (67.39) & 58 (58.59) & $13(48.15)$ & $2(100)$ & $0(0)$ \\
\hline$>5-10$ & $38(21.71)$ & $8(17.39)$ & $23(23.23)$ & $7(25.93)$ & $0(0)$ & $0(0)$ \\
\hline$>10-20$ & $30(17.14)$ & $6(13.04)$ & $18(18.18)$ & $6(22.22)$ & $0(0)$ & $0(0)$ \\
\hline$>20-35$ & $3(1.7 I)$ & I (2.17) & $0(0)$ & I (3.70) & $0(0)$ & $0(0)$ \\
\hline$>35$ & $0(0)$ & $0(0)$ & $0(0)$ & $0(0)$ & $0(0)$ & I (100) \\
\hline \multicolumn{7}{|c|}{ Precipitating factors } \\
\hline No & $109(61.58)$ & $30(65.22)$ & $68(67.33)$ & $10(37.04)$ & I (50.00) & $0(0)$ \\
\hline Yes & $68(38.42)$ & $16(34.78)$ & $33(32.67)$ & $17(62.96)$ & I (50.00) & I (I00) \\
\hline \multicolumn{7}{|c|}{ Follow up (years) } \\
\hline $\begin{array}{l}\text { Median } \\
(\min -\max )\end{array}$ & $I(I-\mid 4)$ & $I(I-13)$ & $I(I-14)$ & $3(I-12)$ & $4.5(I-8)$ & $I(I-I)$ \\
\hline Mean (SD) & $2.8(2.98)$ & $2.89(3.23)$ & $2.39(2.66)$ & $4.15(3.34)$ & $4.5(4.95)$ & I \\
\hline \multicolumn{7}{|l|}{ Outcomes } \\
\hline Control & II $4(64.4 \mathrm{I})$ & 31 (67.39) & $67(66.34)$ & $15(55.56)$ & I (50.00) & $0(0)$ \\
\hline Relapse & $61(34.46)$ & $15(32.6 \mathrm{I})$ & $33(32.67)$ & $12(44.44)$ & I (50.00) & $0(0)$ \\
\hline Death & I $(0.56)$ & $0(0)$ & $0(0)$ & $0(0)$ & $0(0)$ & I (100) \\
\hline $\mathrm{N} / \mathrm{A}$ & I $(0.56)$ & $0(0)$ & I (0.99) & $0(0)$ & $0(0)$ & $0(0)$ \\
\hline \multicolumn{7}{|c|}{ Nail involvement } \\
\hline No & I52 (85.88) & $39(84.78)$ & $87(86.14)$ & $24(88.89)$ & I (50.00) & $I(100)$ \\
\hline Yes & $25(14.12)$ & $7(15.22)$ & $14(13.86)$ & $3(11.11)$ & I (50.00) & $0(0)$ \\
\hline \multicolumn{7}{|c|}{ Joint involvement } \\
\hline No & $173(97.74)$ & $44(95.65)$ & $101(100)$ & 25 (92.59) & $2(100)$ & $I(100)$ \\
\hline Yes & $4(2.26)$ & $2(4.35)$ & $0(0)$ & $2(7.4 I)$ & $0(0)$ & $0(0)$ \\
\hline
\end{tabular}




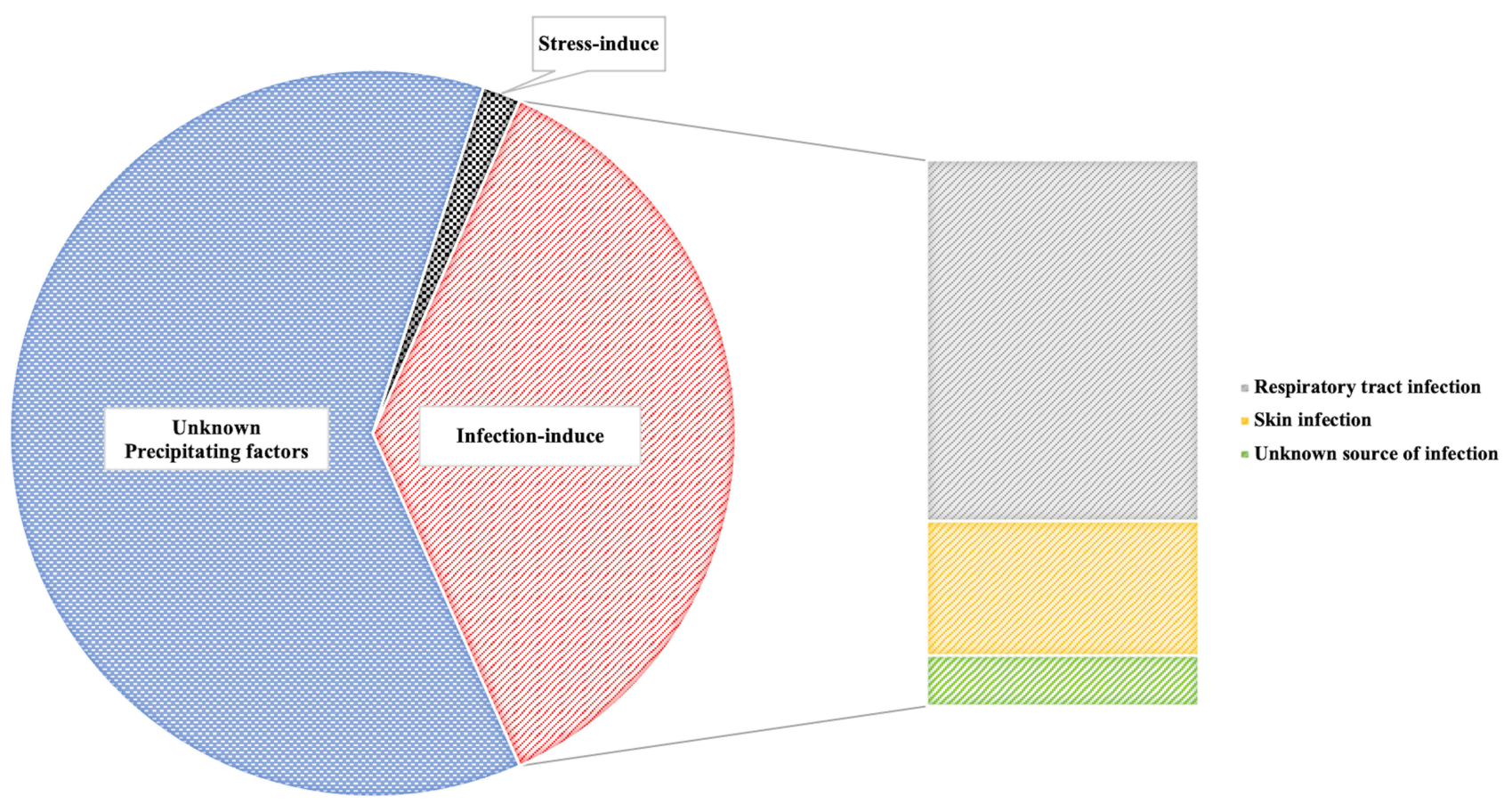

Figure I Precipitating causes of pediatric psoriasis in the study population.

The mean follow-up period was 2.8 years (SD 2.98). The outcomes at the patients' last visit were classified to control, relapse, and death. Majority of pediatric psoriasis patients had favorable outcomes, 114 cases $(64.41 \%)$ had disease in control, 62 cases (34.46\%) with frequent relapse of more than 5 times/year, and one erythrodermic psoriasis was fatal.

\section{Discussion}

There were few published epidemiological studies and treatment information regarding psoriasis in children. Therefore, the available treatment information in this population is helpful even though the traditional treatment that still remains the main treatment in most countries of the world. The present study revealed a 20 -year retrospective study of pediatric psoriasis from a tertiary care referral hospital in Thailand. The present study showed the mean age of 10.50 (SD 4.80) which is similar to the previous study with a peak age of onset of $10-11$ years. ${ }^{11}$ This finding supports an epidemiological database that approximately $30-50 \%$ of adults with psoriasis developed psoriasis before 20 years of age. Therefore, future treatment action focusing on psoriasis in children, providing early treatment, and early detection of associated comorbidity may affect the long-term outcome of adult psoriasis in the future.
As mentioned earlier, there were five types of psoriasis in the study population. The two most common types were guttate psoriasis $(57.06 \%)$ - represented as few to numerous small drop-like erythematous scaly papules, ${ }^{19}$ and plaque psoriasis $(25.99 \%)$. This finding is similar to the common findings among pediatric psoriasis that found these two types more frequent as compared to the other types. ${ }^{14}$ As a referral center, the present study revealed a high number of uncommon severe form of psoriasis; generalized pustular psoriasis (GPP), as high as $15.25 \%$. GPP is a rare variant of psoriasis that represents sterile superficial pustules with aggressive presentation ${ }^{20}$ and is recalcitrant to treatment. ${ }^{21}$ The youngest age diagnosed with GPP in the study population was 2-month-old (Figure 3A). Figure 3 shows some GPP cases with generalized pustular eruptions in the study population. GPP usually required systemic treatment. In the study population, acitretin was used as the main systemic treatment among GPP patients with favorable responses. Even though biologic therapies such as etanercept, adalimumab and ustekinumab ${ }^{9}$ are approved in pediatric psoriasis, the present study still had no experience with the mentioned treatment.

The present study revealed that different types of psoriasis showed differences in outcomes. The most severe case in the study population was erythrodermic psoriasis 
Table 2 Factors Associated with MetS in the Study Population

\begin{tabular}{|c|c|c|c|c|c|}
\hline \multirow[t]{2}{*}{ Variable } & \multicolumn{2}{|c|}{ Metabolic Syndrome } & \multirow[t]{2}{*}{ Relative Risk } & \multirow[t]{2}{*}{$95 \% \mathrm{Cl}$} & \multirow[t]{2}{*}{ p-value } \\
\hline & Yes & No & & & \\
\hline \multicolumn{6}{|l|}{ Sex } \\
\hline Male & $19(36.54)$ & $59(47.20)$ & & & \\
\hline Female & $33(63.46)$ & $66(52.80)$ & 0.73 & $0.45-1.18$ & 0.19 \\
\hline \multicolumn{6}{|l|}{ Age (years) } \\
\hline$\leq 12 \mathrm{yr}$ & $25(48.08)$ & $82(65.60)$ & & & \\
\hline$>12 \mathrm{yr}$ & $27(51.92)$ & $43(34.40)$ & 0.61 & $0.39-0.95$ & 0.029 \\
\hline \multicolumn{6}{|l|}{ Type of psoriasis } \\
\hline Plaque psoriasis & $15(28.85)$ & $31(24.80)$ & - & & \\
\hline Guttate psoriasis & $29(55.77)$ & $72(57.60)$ & 1.14 & $0.68-1.90$ & 0.63 \\
\hline Generalized pustular psoriasis & $8(15.38)$ & $19(15.20)$ & 1.10 & $0.54-2.25$ & 0.79 \\
\hline Inverse & $0(0)$ & $2(1.60)$ & 0.41 & $0.02-8.99$ & 0.33 \\
\hline Erythroderma & $0(0)$ & I $(0.80)$ & 0.68 & $0.03-17.61$ & 0.49 \\
\hline \multicolumn{6}{|l|}{ Family history } \\
\hline No & $2(3.85)$ & $3(2.40)$ & - & & \\
\hline Yes & $42(80.77)$ & $110(88.00)$ & 0.69 & $0.23-2.08$ & 0.54 \\
\hline$N / A$ & $8(15.38)$ & $12(9.60)$ & 0.69 & $0.38-1.25$ & 0.25 \\
\hline
\end{tabular}

and the final outcome of this patient was fatal. The patient had generalized erythroderma with exfoliative dermatitis on the entire body surface area. Secondary bacterial cutaneous infection and septicemia was documented before the mortality. The patient received systemic treatment (acitretin) for the disease control for 6 months without improvement. Even though approval of biologic therapies for psoriasis has dramatically altered the treatment landscape for individuals with psoriasis, ${ }^{22}$ however, the mentioned treatment was unavailable in the study population due to no funding issue. A choice of biologic therapy in a severe form of pediatric psoriasis may provide a better treatment outcome in the future.

Precipitating factors are more commonly identified in childhood psoriasis than in adult onset disease. ${ }^{22,23}$ This sequence was also found in the study population that revealed $38.42 \%$ of cases that reported precipitating factors and infections as the most frequent cause, Figure 1.

Association of increased rates of hyperlipidemia, obesity, hypertension, and diabetes mellitus were also found in pediatric psoriasis like in adults. ${ }^{8}$ These findings are potential risk factors of MetS. However, due to controversies regarding the definition of MetS and the lack of consensus thresholds for the single components in children and adolescents, there is no internationally accepted diagnostic criteria and no cut-off values for MetS available. ${ }^{15}$ There is common agreement that the following four major cardiovascular risk factors are used for defining MetS in adults: (1) Hyperinsulinemia/disturbed glucose metabolism/insulin resistance, (2) Arterial hypertension, (3) Dyslipidemia, and (4) Abdominal obesity, which are components of the MetS. According to these definitions, a child is diagnosed with MetS if a predefined critical value exceed for three or more of these risk factors. ${ }^{8,15-18}$ Based on the mentioned definition, the present study revealed 52 cases $(29.37 \%)$ with MetS.

Like in adults, pediatric psoriasis comorbidity screening guidelines were proposed. ${ }^{17,24-26}$ The cut off screening age of each comorbidity may vary. For example; screening for insulin resistance starting at age 10 years or at the onset of puberty regardless of the presence of risk factors, universal lipid screening should be performed during the following 2 age ranges: 9 to 11 years old and 17 to 21 years old, while the screening for overweight and obesity using BMI percentile and screening for hypertension should be started early at 2 and 3 years of age, respectively. ${ }^{17}$ Like other countries, Thailand is now facing a problem of childhood obesity due to rapid socio-economic transition. 


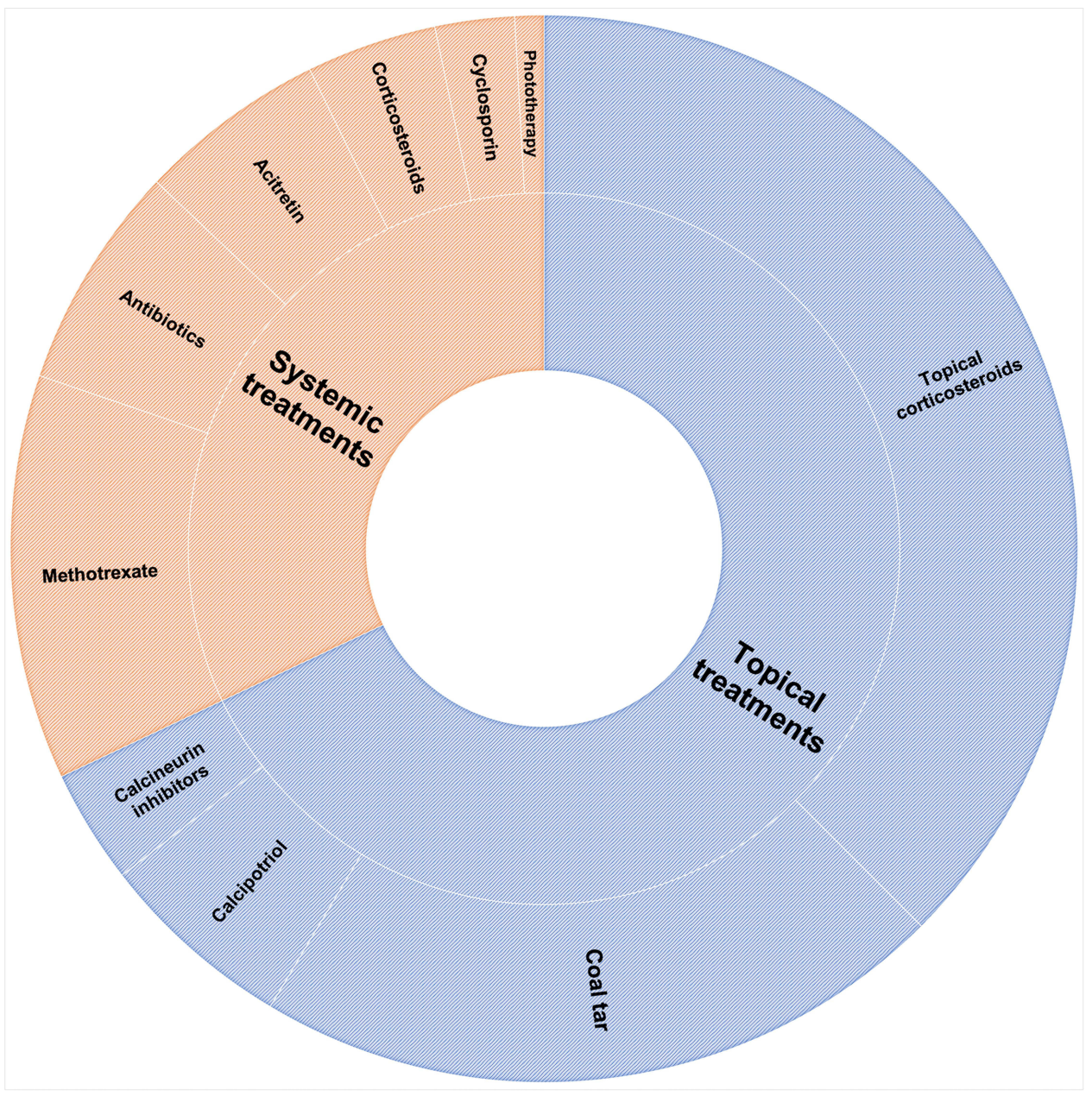

Figure 2 Psoriasis treatments among the study population.

The mean BMI in the study population was 19.10 (SD 5.44). The present BMI was higher than the previous study in Thai children in $2008^{27}$ that revealed the mean BMI of 15.7 in girls and 16.2 in boys. This finding supports to the early detection of obesity and MetS in pediatric psoriasis population. Among 52 cases of MetS in the study population, pediatric psoriasis patients over the age of 12 years old developed MetS 27 out of 70 cases (0.38) compared to the patients younger than 12 years old (25 out of 107 cases, 0.23 ), absolute risk reduction $=0.15,95 \%$ CI $0.01-$ $0.29, \mathrm{P}=0.029$.

The main limitation of this study was a retrospective study design that resulted in missing some unrecorded data. Some pediatric psoriasis patients presented were of mild severity and might have been underdiagnosed. ${ }^{28}$ Even though there was no information on the experience of the new biologic therapy in the study, most of pediatric psoriasis had favorable outcomes with the traditional topical and systemic treatments. However, future study with a new biologic treatment option in an Asian population will be certainly recorded as soon as the treatment available in the study population.

\section{Conclusion}

The present study revealed that there was $15 \%$ increased MetS in the pediatric psoriasis patients over the age of 12 years old as compared to the patients of prepubertal age ( $\leq 12$ years old). Like in adults, pediatric psoriasis comorbidity screening is recommended. The overall outcomes of pediatric psoriasis were good even with traditional topical and systemic treatments provided in the study population. However, biologic therapy would be an alternative option in severe recalcitrant pediatric psoriasis cases in the future. 


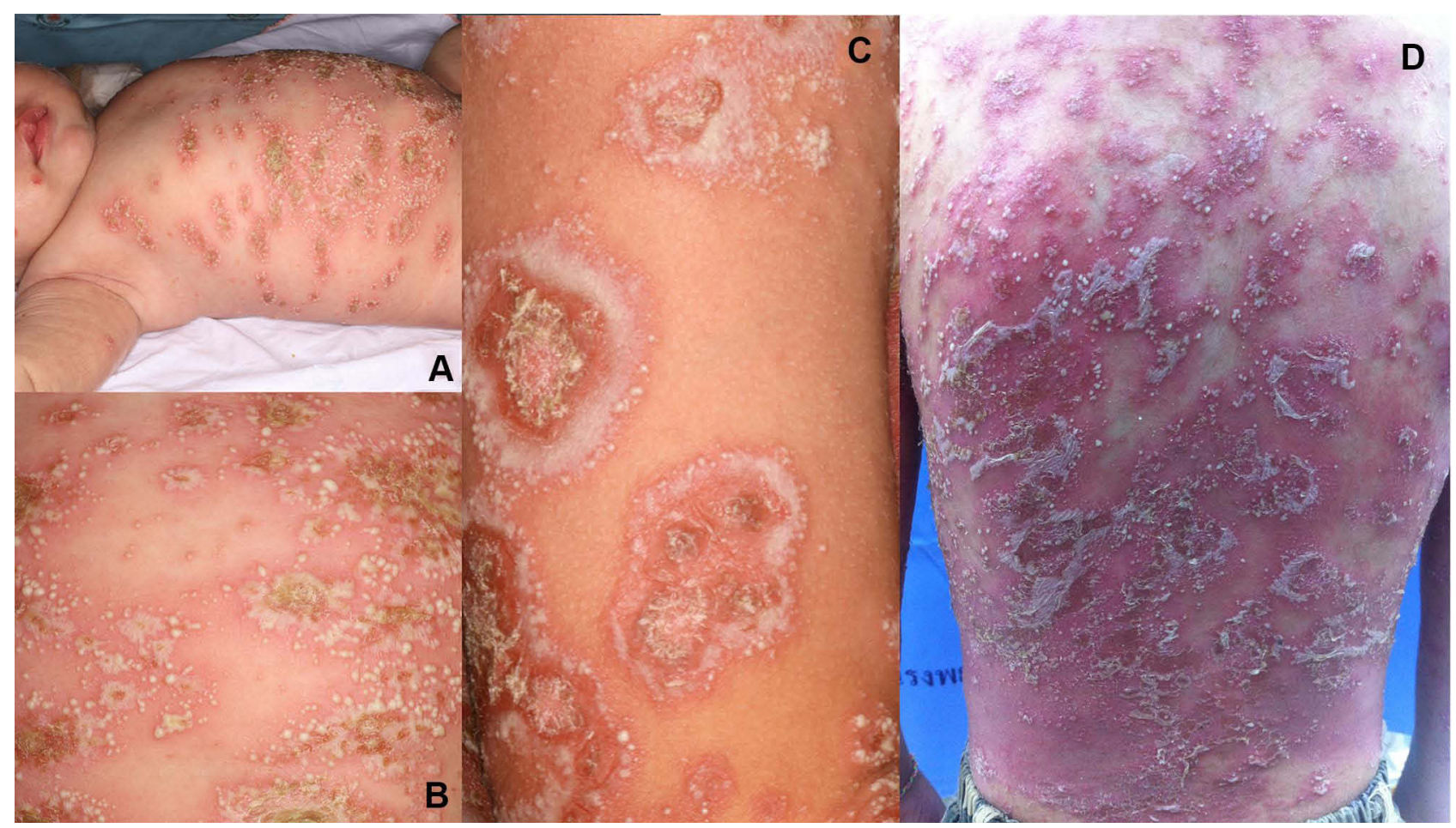

Figure 3 GPP cases with generalized pustular eruptions in the study population. (A) Infant diagnosed with GPP in the study population was 2-month-old (3A), generalized pustular eruptions in the older GPP patients (B-D).

\section{Abbreviations}

MetS, metabolic syndrome; GPP, generalized pustular psoriasis.

\section{Ethical Approval and Informed Consent}

The study was approved by the institutional review board of Faculty of Medicine, Khon Kaen University, Thailand (IRB no. \#HE631221) before enrolling any participants. The authors covered patient data confidentiality and compliance with the Declaration of Helsinki. The present study used data from medical records/documents/ records/image recordings that were previously collected for purposes other than research (eg, normal care or normal diagnosis) and did not affect the subjects' rights and well-being, thus waiving the informed consent was approved by the IRB of the Faculty of Medicine, Khon Kaen University, Thailand (IRB no. \#HE631221).

\section{Acknowledgments}

We would like to acknowledge Ms. Duangdao Sriruengrat for the statistical analysis and Mr. Gurdeep Singh, for editing the manuscript via publication clinic KKU, Thailand.

\section{Funding}

The study was granted by the Faculty of Medicine, Khon Kaen University, Thailand. (Grant no. \#IN63276).

\section{Disclosure}

The authors report no conflicts of interest in this work.

\section{References}

1. Bronckers IMGJ, Paller AS, West DP, et al. A comparison of psoriasis severity in pediatric patients treated with methotrexate vs biologic agents. JAMA Dermatol. 2020;156(4):384-392. doi:10.1001/ jamadermatol.2019.4835

2. Żychowska M, Reich A, Maj J, Jankowska-Konsur A, Szepietowski JC. Impact of childhood psoriasis on caregivers' quality of life, measured with family dermatology life quality index. Acta Derm Venereol. 2020;100(15):adv00244. doi:10.2340/00015555-3602

3. Salman A, Yucelten AD, Sarac E, Saricam MH, Perdahli-Fis N. Impact of psoriasis in the quality of life of children, adolescents and their families: a cross-sectional study. An Bras Dermatol. 2018;93 (6):819-823. doi:10.1590/abd1806-4841.20186981

4. Varni JW, Globe DR, Gandra SR, Harrison DJ, Hooper M, Baumgartner S. Health-related quality of life of pediatric patients with moderate to severe plaque psoriasis: comparisons to four common chronic diseases. Eur $J$ Pediatr. 2012;171(3):485-492. doi:10.1007/s00431-011-1587-2

5. Micali G, Verzì AE, Giuffrida G, Panebianco E, Musumeci ML, Lacarrubba F. Inverse psoriasis: from diagnosis to current treatment options. Clin Cosmet Investig Dermatol. 2019;12:953-959. doi:10.2147/CCID.S189000 
6. Caroppo F, Galderisi A, Ventura L, Fortina AB. Metabolic syndrome and insulin resistance in pre-pubertal children with psoriasis. Eur J Pediatr. 2021;180(6):1739-1745. doi:10.1007/ s00431-020-03924-w

7. Hunjan MK, Maradit Kremers H, Lohse C, Tollefson M. Association between obesity and pediatric psoriasis. Pediatr Dermatol. 2018;35 (5):e304-5. doi:10.1111/pde.13539

8. Augustin M, Glaeske G, Radtke MA, Christophers E, Reich K, Schäfer I. Epidemiology and comorbidity of psoriasis in children. Br J Dermatol. 2010;162(3):633-636. doi:10.1111/j.13652133.2009.09593.x

9. Dogra S, Mahajan R. Biologics in pediatric psoriasis - efficacy and safety. Expert Opin Drug Saf. 2018;17(1):9-16. doi:10.1080/ 14740338.2018.1391787

10. Papp K, Thaçi D, Marcoux D, et al. Efficacy and safety of adalimumab every other week versus methotrexate once weekly in children and adolescents with severe chronic plaque psoriasis: a randomised, double-blind, Phase 3 trial. Lancet Lond Engl. 2017;390 (10089):40-49. doi:10.1016/S0140-6736(17)31189-3

11. Kwon HH, Na SJ, Jo SJ, Youn JI. Epidemiology and clinical features of pediatric psoriasis in tertiary referral psoriasis clinic. J Dermatol. 2012;39(3):260-264. doi:10.1111/j.1346-8138.2011.01452.x

12. Paller AS, Schenfeld J, Accortt NA, Kricorian G. A retrospective cohort study to evaluate the development of comorbidities, including psychiatric comorbidities, among a pediatric psoriasis population. Pediatr Dermatol. 2019;36(3):290-297. doi:10.1111/pde.13772

13. Griffiths CEM, van der Walt JM, Ashcroft DM, et al. The global state of psoriasis disease epidemiology: a workshop report. Br J Dermatol. 2017;177(1):e4-7. doi:10.1111/bjd.15610

14. Bronckers IMGJ, Paller AS, van Geel MJ, van de Kerkhof PCM, Seyger MMB. Psoriasis in children and adolescents: diagnosis, management and comorbidities. Paediatr Drugs. 2015;17(5):373-384. doi:10.1007/s40272-015-0137-1

15. Christian Flemming GM, Bussler S, Körner A, Kiess W. Definition and early diagnosis of metabolic syndrome in children. $J$ Pediatr Endocrinol Metab JPEM. 2020;33(7):821-833. doi:10.1515/jpem2019-0552

16. Weihe $\mathrm{P}$, Weihrauch-Blüher S. Metabolic syndrome in children and adolescents: diagnostic criteria, therapeutic options and perspectives. Curr Obes Rep. 2019;8(4):472-479. doi:10.1007/s13679-019-00357-x
17. Osier E, Wang AS, Tollefson MM, et al. Pediatric psoriasis comorbidity screening guidelines. JAMA Dermatol. 2017;153(7):698-704. doi:10.1001/jamadermatol.2017.0499

18. Dauden E, Blasco AJ, Bonanad C, et al. Position statement for the management of comorbidities in psoriasis. J Eur Acad Dermatol Venereol. 2018;32(12):2058-2073. doi:10.1111/jdv.15177

19. Bhutani T, Kamangar F, Cordoro KM. Management of pediatric psoriasis. Pediatr Ann. 2012;41(1):e1-7. doi:10.3928/0090448120111209-08

20. Twelves S, Mostafa A, Dand N, et al. Clinical and genetic differences between pustular psoriasis subtypes. $J$ Allergy Clin Immunol. 2019;143(3):1021-1026. doi:10.1016/j.jaci.2018.06.038

21. Fortina AB, Bardazzi F, Berti S, et al. Treatment of severe psoriasis in children: recommendations of an Italian expert group. Eur $J$ Pediatr. 2017;176(10):1339-1354. doi:10.1007/s00431-017-2985-x

22. Eichenfield LF, Paller AS, Tom WL, et al. Pediatric psoriasis: evolving perspectives. Pediatr Dermatol. 2018;35(2):170-181. doi:10.1111/pde. 13382

23. Raychaudhuri SP, Gross J. A comparative study of pediatric onset psoriasis with adult onset psoriasis. Pediatr Dermatol. 2000;17 (3):174-178. doi:10.1046/j.1525-1470.2000.01746.x

24. Kang BY, O'Haver J, Andrews ID. Pediatric psoriasis comorbidities: screening recommendations for the primary care provider. $J$ Pediatr Health Care. 2021;35(3):337-350.

25. Kittler NW, Cordoro KM. Pediatric psoriasis comorbidities. Skin Ther Lett. 2020;25(5):1-6.

26. Caroppo F, Ventura L, Belloni fortina A. High blood pressure in normal-weight children with psoriasis. Acta Derm Venereol. 2019;99(3):329-330. doi:10.2340/00015555-3076

27. Yamborisut U, Sakamoto N, Visetchart P, Tontisirin K. Central body fat distribution indices in Thai preschool children. Open J Pediatr. 2012;2(1):47-52. doi:10.4236/ojped.2012.21007

28. Onsoi W, Chaiyarit J, Techasatian L. Common misdiagnoses and prevalence of dermatological disorders at a pediatric tertiary care center. J Int Med Res. 2020;48(2):300060519873490. doi:10.1177/ 0300060519873490
Psoriasis: Targets and Therapy

\section{Publish your work in this journal}

Psoriasis: Targets and Therapy is international, peer-reviewed, open access journal focusing on psoriasis, nail psoriasis, psoriatic arthritis and related conditions, identification of therapeutic targets and the optimal use of integrated treatment interventions to achieve improved outcomes and quality of life. Visit http://www.dovepress. com/testimonials.php to read real quotes from published authors. 